\title{
Synthesis and Characterization of Poly(azomethine ester)s with a Pendent Dimethoxy Benzylidene Group
}

\author{
B. Joy Vasanthi*, L. Ravikumar \\ C.B.M. College, Coimbatore, India \\ Email: ${ }^{*}$ joyvasanthi@yahoo.co.in
}

Received February 4, 2013; revised March 25, 2013; accepted April 5, 2013

Copyright (C) 2013 B. Joy Vasanthi, L. Ravikumar. This is an open access article distributed under the Creative Commons Attribution License, which permits unrestricted use, distribution, and reproduction in any medium, provided the original work is properly cited.

\begin{abstract}
Recently, soluble poly(azomethine ester)s with good thermal stability and liquid crystalline properties are much sought after in opto-electronic field. One such attempt was to synthesize poly(azomethine ester)s with a pendent group. In this study, the newly synthesized diacid monomer benzalaniline 3'-4'dimethoxy terepthalic acid was condensed with two diol monomers to get the polymers with pendent benzylidene group. The diacid monomer was characterized by UV, IR, NMR and CHNS analysis. The polymers were characterized by IR, TGA, and for liquid crystalline property. Polymer-I showed the highest thermal stability upto $335^{\circ} \mathrm{C}$. Polymer-II exhibited liquid crystalline nature along with good solubility and thermal stability.
\end{abstract}

Keywords: Poly(azomethine ester); Synthesis; Phosphorylation; Solubility; Liquid Crystalline

\section{Introduction}

Aromatic polymers containing both ester and azomethine units are a type of high-performance polymers with excellent thermal, physical and mechanical properties and are utilized in various fields such as electric, electronic, photonics and in industrial material field [1-6]. It has been reported that the ester group increases the electrical conductivity of copolymers in poly(azomethine-ester) via two manners i.e. by increasing the flexibility of the chain and making the charge carrier movement more along the chain [7]. It has also been reported that the presence of ether group in the aldehyde fragment of polymer causes increase of energy gap and increase of amorphous properties. Poly(azomethine) with oxygen atom in the backbone was found to be more amorphous and more luminescent properties [8]. But their poor solubility in organic solvents often restricts its use for many applications. Thus, it is clear that various structural changes should be made in the poly(azomethine ester)'s chain to obtain better solubility and its application in various fields [9-15]. Some of the reported methods to improve the processability of conjugated poly(azomethine)s are by incorporation of unsymmetrical or symmetrical substitutions

\footnotetext{
"Corresponding author.
}

in the main-chain aromatic benzene rings with flexible alkyl or alkoxy side chains and reversible Lewis acidbase complexation [16-19]. Moreover, it has been already found that introduction of groups with $\mathrm{sp}^{3}$-hybridized atoms $\left(-\mathrm{CR}_{2}-\right)$, ether linkage, and pendant phenyl groups can improve the solubility of polyesters [20-26]. It has been reported that the presence of oxygen atom contributes to increase in the basicity of the schiff base nitrogen atom in the polymer, resulting in the stronger interaction to the acid and increasing the solubility of poly(azomethine) [27]. Besides, the solubility of the conjugated polymers can be improved by incorporating relatively long and flexible side chains in the polymer backbone [28-30].

Mikroyannidis reported polyisothalamide with N-benzilidene pendent group, in that $\mathrm{N}$-benzylidene pendent group enhances the solubility of the polymer [31]. Recently systematic studies on rigid polymers, mainly on aromatic polyesters containing side chain have shown that the melting temperature decreases as the length of the side chain increases and that these polymers are able to form a novel layered mesophase [32]. Krigbaum et al., reported a novel polyamide preparation by phosphorylation method [33]. Higashi et al., have prepared aromatic carboxylic esters in the presence of poly(ethyl phosphate) 
in DMF in moderate yields [34]. However, the reaction has never been applied to the preparation of polyesters with a pendent group from diacid and dihydroxy compounds. It was also found that the coupling reaction between carboxyl and amino or hydroxyl components are accomplished without oxidation when diphenylphosphate is used in pyridine [35].

In this paper, we report the preparation and characterization of two polymers with a pendent dimethoxy benzylidene group - one having notable number of aromatic rings, azomethine and an oxygen atom in the back-bone and the other with less number of aromatic rings and methylene spacer in the main chain. The polymers were synthesized by phosphorylation method using dichloro phenyl phosphine/pyridine and $\mathrm{LiCl}$ dissolved in DMFas solvent.

\section{Materials and Methods}

\subsection{Materials}

2-aminoterepthalic acid, 3'-4'dimethoxy benzaldehyde, (Aldrich), Dichlorophenyl phosphine (Merch), Lithium chloride (Aldrich) were used as received. 4-4'diamino oxydiphenylene, vanillin, bisphenol-A, pyridine and DMF were all purified by using standard procedures.

\subsection{Monomer Synthesis}

\subsubsection{Synthesis of Benzalaniline 3'-4'dimethoxy Terepthalic Acid}

2-aminoterepthalic acid (1 mol) and 3, 4-dimethoxy benzaldehyde $(1 \mathrm{~mol})$ were condensed with DMF and refluxed using a Dean-stark apparatus. After 2 hrs of refluxing, excess DMF was removed and the products were poured into ice-cold water. The resulting yellow colored precipitate was washed with water, with ethanol and vacuum dried (Scheme 1). Yield: $-75 \% \mathrm{M}$. Pt: $230^{\circ} \mathrm{C}$.

\subsubsection{Synthesis of N, N'-Bis(4-hydroxy-3-methoxy benzal)4-4'-diamino oxydiphenylene}

The above monomer was prepared by condensing 44'diamino oxydiphenylene with vanillin in 1:2 mole ratio in the usual schiff base condensation (Scheme 2).

\subsection{Synthesis of Polymer}

In phosphorylation method, a mixture of equimolar amounts of diacid monomer $(2.5 \mathrm{mmol})$, diol $(2.5 \mathrm{mmol})$ and dichlorophenyl phosphine $(0.3 \mathrm{ml})$ in DMF $(15 \mathrm{ml})$ in which $\mathrm{LiCl}(1 \mathrm{gm})$ was dissolved and pyridine $(3 \mathrm{ml})$ was refluxed at $140^{\circ} \mathrm{C}$ for $3-4$ hours. The viscous mixture was cooled and poured into water. The resulting polymer was washed with $5 \% \mathrm{Na}_{2} \mathrm{CO}_{3}$ solution and with dil. $\mathrm{HCl}$ to remove the un-reacted monomers. Then it was washed with water, with alcohol and dried in vacuum.

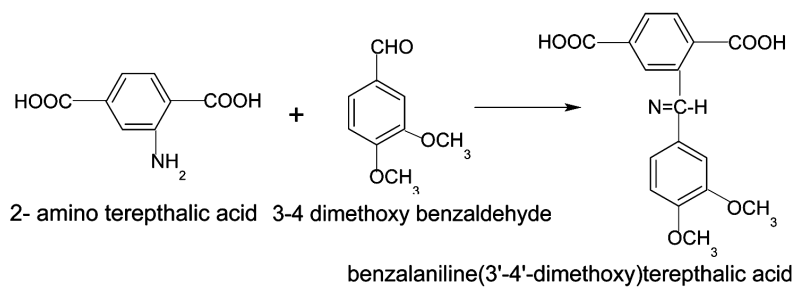

Scheme 1. Synthetic route for the preparation of diacid monomer.

The scheme is represented in Scheme 3.

\section{Experimental}

\section{Characterization Methods}

Elemental analysis for the monomer was done with a Thermo Fennigan Flash EA-1112 C H N S analyzer. ${ }^{1} \mathrm{H}$ NMR Spectra was obtained using a $400 \mathrm{MH}_{\mathrm{Z}}$ spectrometer with DMSO- $\mathrm{d}_{6}$.

I.R. spectra of the monomers and the polymers were recorded in a Shimadzu spectrophotometer with $\mathrm{KBr}$ Pellets. UV-Visible spectra for the monomer was recorded in DMF solvent in a closed cell at room temperature with a Hitachi UV-Visible spectrophotometer.

Solubility of the polyesters was determined in various solvents. The polymers $(30-50 \mathrm{mg})$ were taken in small stoppered test tubes containing $1 \mathrm{ml}$ of the solvent. The mixture was kept for 24 hours with occasional shaking. If dissolution had not occurred, the mixture was slowly heated up to the boiling point of the solvent for few minute, if necessary.

The synthesized polyesters were characterized by viscosity measurements in DMF in Ubbelohyde viscometer at $20^{\circ} \mathrm{C}$.

For thermo gravimetric analysis, the thermo grams ware recorded on a Perkin-Elmer 7 Series Thermal analysis system of $\mathrm{V}_{4}$-IC DuPont instrument with a heating rate of $20^{\circ} \mathrm{C}$ per minute in Nitrogen atmosphere. The sample size varied from 4 to $10 \mathrm{mg}$.

For Polarizing Microscopic Studies, the monomer and the polymers were melted using a hot plate on a glass plate with cover slip. The melt was examined under polarizing microscope. The isotropization temperature and the melt temperature of the polymers could not be followed due to the non-availability of the hot stage with the instrument. Hence the texture reported in this paper was taken after melting the sample on a hot plate and gradually cooling with a cover slip.

\section{Results and Discussion}

\subsection{Monomer Synthesis}

The new diacid monomer was prepared by the condensation reaction between 2-amino terepthalic acid and vera- 


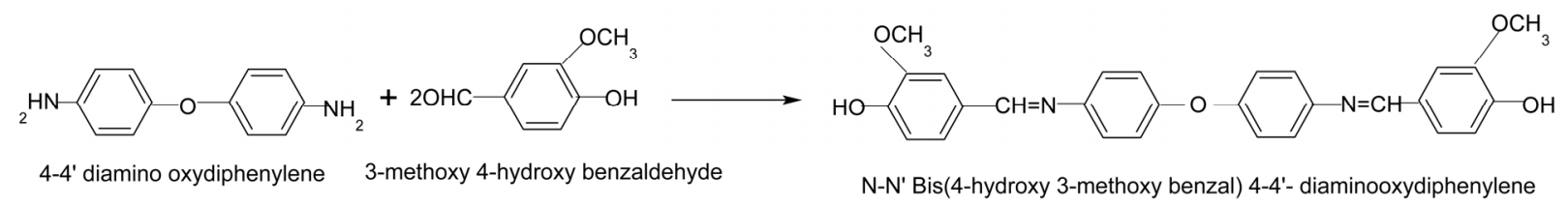

Scheme 2. Synthetic route for the preparation of diol monomer.

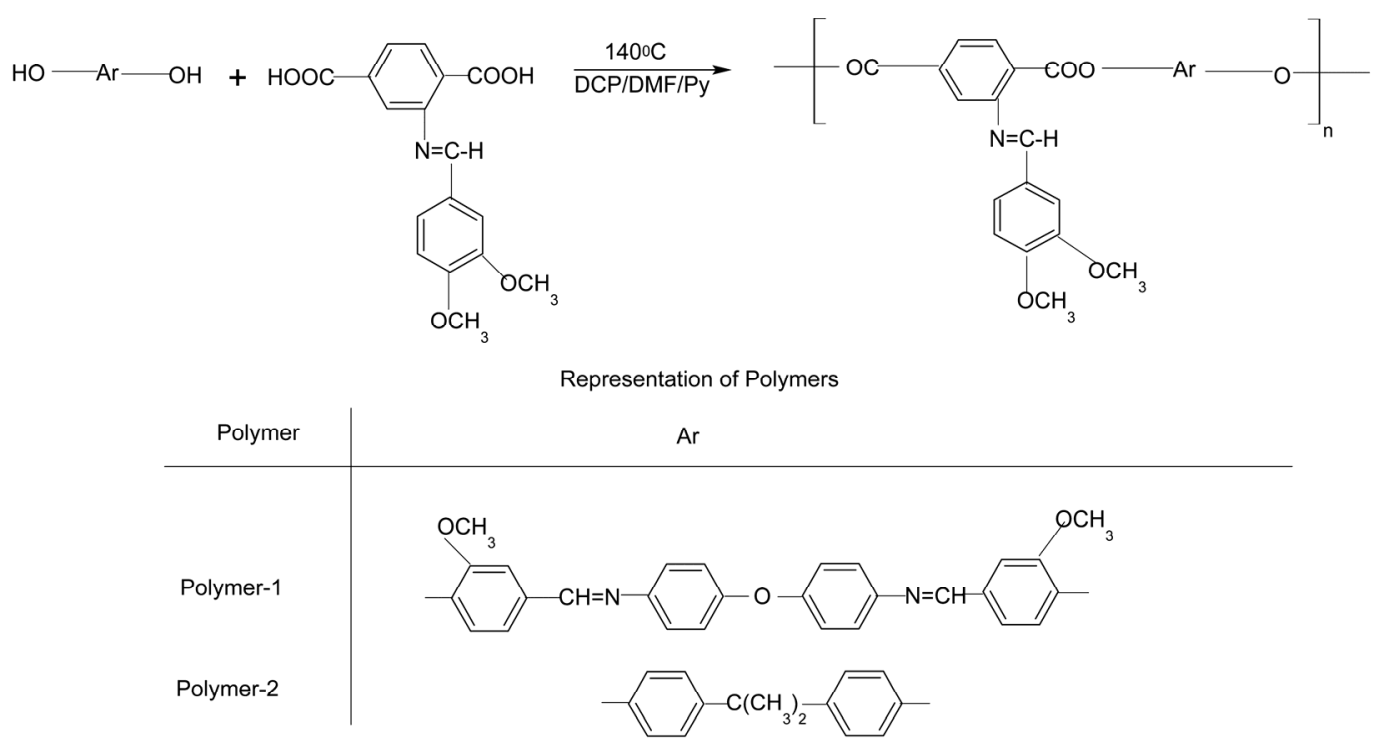

Scheme 3. Synthetic route for the preparation of polymer.

traldehyde. The synthetic route is given as Scheme $\mathbf{1}$. Elemental analysis as given in Table 1 supported the formation of the monomer and confirmed with the calculated data.

In the IR spectrum (Figure 1), the disappearance of $\mathrm{NH}_{2}$ stretching frequency of at $3505 \mathrm{~cm}^{-1}$ and $3388 \mathrm{~cm}^{-1}$ and the appearance of imine $-\mathrm{CH}$ stretching frequency at $2917 \mathrm{~cm}^{-1}$ along with the $\mathrm{N}=\mathrm{CH}$ stretching frequency at $1671 \mathrm{~cm}^{-1}$ and the methoxy stretching frequency at 1021 $\mathrm{cm}^{-1}$ support the formation of the monomer. The IR spectrum of the monomer shows a very broad absorption band $2500-3000 \mathrm{~cm}^{-1}$ i.e. the characteristic O-H stretching frequency of carboxylic acids, which often looks like distorted baseline and has reached above $3000 \mathrm{~cm}^{-1}$. The $\mathrm{C}=\mathrm{O}$ stretching frequency at $1680-1725 \mathrm{~cm}^{-1}$ of carboxylic acids can be seen as strong band which further confirms the monomer formation.

In the ${ }^{1} \mathrm{H}-\mathrm{NMR}$ spectrum (Figure 2), the integral areas for the different groups are $\delta 9.9 \mathrm{ppm}(2 \mathrm{H}-\mathrm{COOH}), \delta 7.9$ ppm (s, $1 \mathrm{H}, \mathrm{HC}=\mathrm{N}), \delta 7.8 \mathrm{ppm}(\mathrm{d}, 3 \mathrm{H}$ phenyl), $\delta 7.4 \mathrm{ppm}$ (s, $1 \mathrm{H}$ phenyl), $\delta 7 \mathrm{ppm}$ (d, 2H phenyl), $\delta 3.8 \mathrm{ppm}(\mathrm{d}, 3$ $\left.\mathrm{H}-\mathrm{OCH}_{3}\right), \delta 3.8 \mathrm{ppm}\left(\mathrm{s}, 3 \mathrm{H}-\mathrm{OCH}_{3}\right)$ and $\delta 2.5 \mathrm{ppm}$ is due to solvent. The integral at $\delta 7.9 \mathrm{ppm}(\mathrm{s}, 1 \mathrm{H})$ is the characteristic proton of the $\mathrm{CH}=\mathrm{N}$ group. The shift to lower field is due to the conjugation between unshared pair of electrons on the nitrogen atom and the aromatic ring.

The UV absorption spectrum of the monomer shows

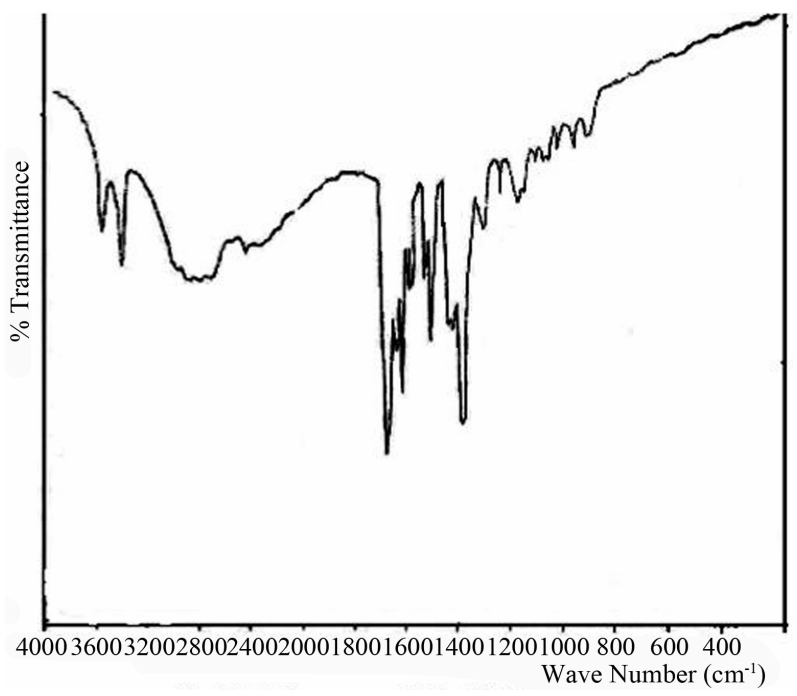

Figure 1. IR spectrum of diacid monomer.

$\pi-\pi^{*}$ absorption at $370 \mathrm{~nm}$ of the azomethine group (Figure 3).

Structural characterization of the monomer as evidenced by ${ }^{1} \mathrm{H}-\mathrm{NMR}$, IR and UV spectroscopy agreed with the synthetic route adopted.

The analyzed properties of the new diacid monomer are listed in Table 1.

The synthetic route for the preparation of diol monomer is given in Scheme 2 and its characterization has 
Table 1. Characterisation of the monomer.

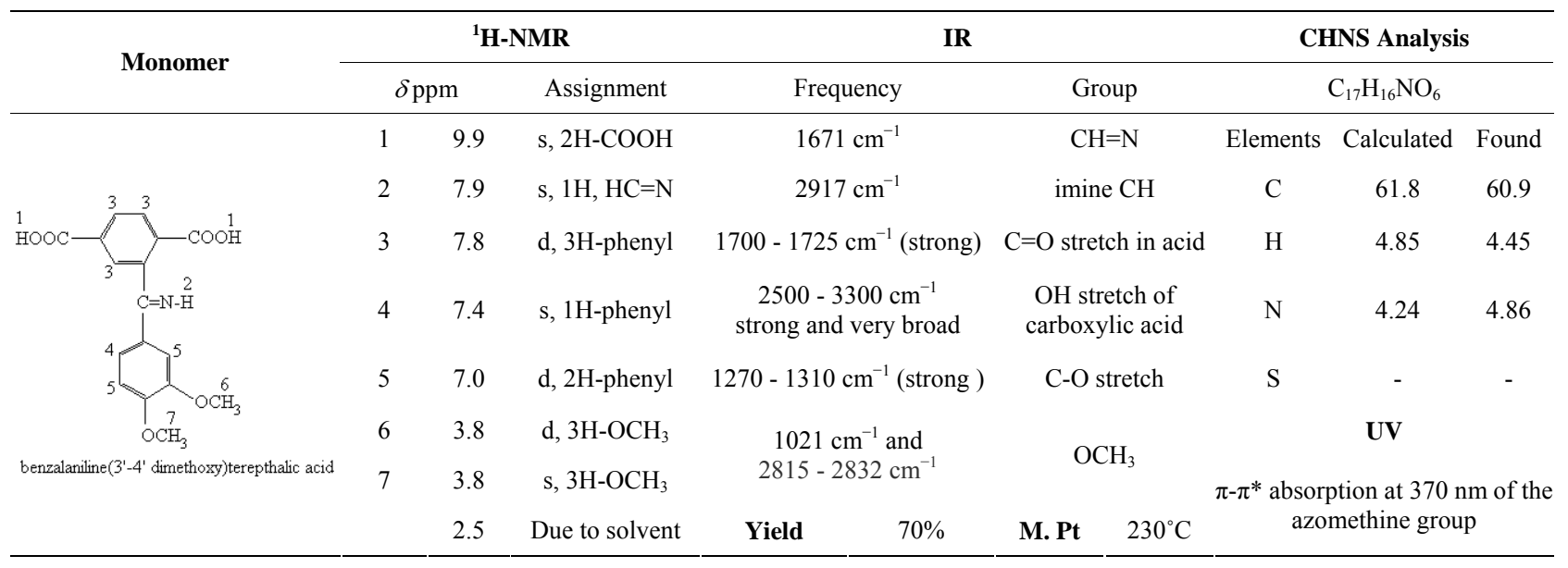

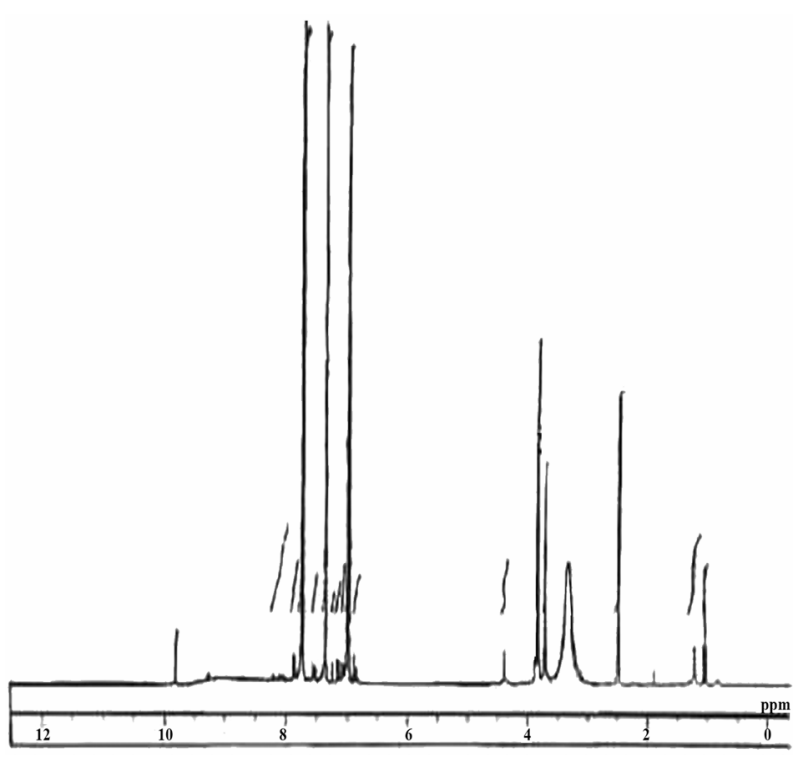

Figure $2 .{ }^{1} \mathrm{H}$-NMR spectrum of diacid monomer.

already been submitted [36].

\subsection{Polymer Synthesis}

The synthetic route for polymer preparation is given in Scheme 2 . The polyesters were prepared using dichlorophenylphosphine in pyridine/DMF solvent containing $\mathrm{LiCl}$. In polycondensation, $\mathrm{LiCl}$ was added to improve the dissolution of polymers, because solubility of the polymers in reaction media usually affects the molecular weight of the resulting polymers $[37,38]$.

Both the polymers were characterized by IR, TGA, solubility, viscosity and for liquid crystalline properties. The IR Spectra of polymers I and II (Figures 4 and 5) shows the disappearance of carboxylic acid group at $1700 \mathrm{~cm}^{-1}$ and the appearance of ester group frequency at $1735 \mathrm{~cm}^{-1}$ and $1750 \mathrm{~cm}^{-1}$ confirms the formation of ester group. The C-0 stretching of ester can also be seen

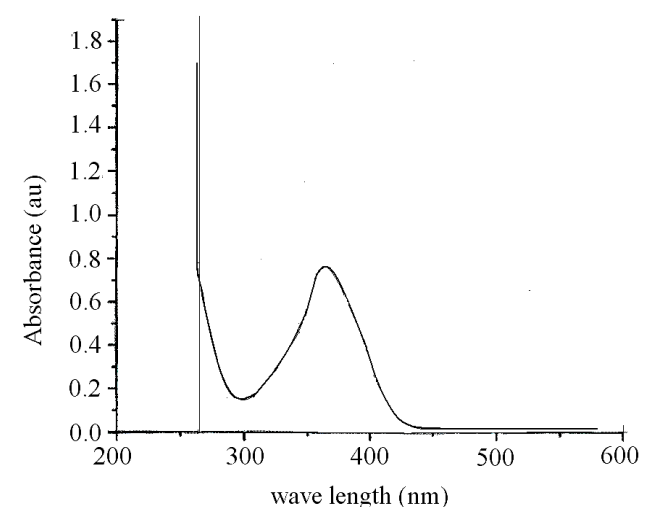

Figure 3. UV-visible spectrum of diacid monomer.

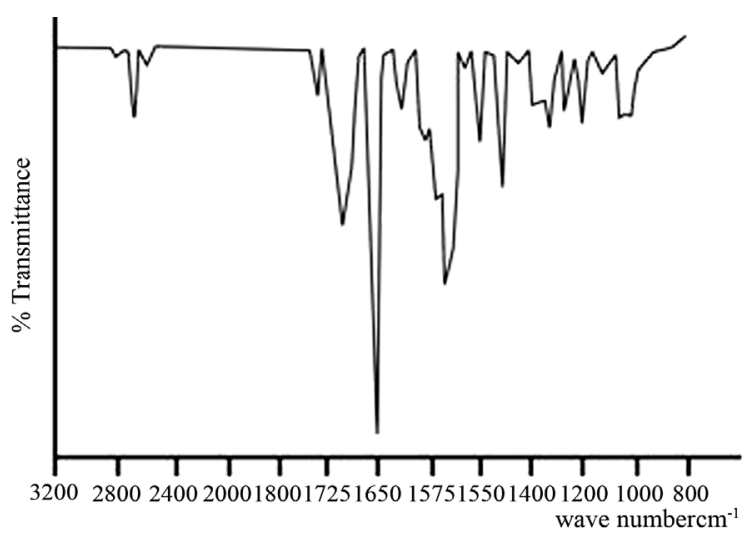

Figure 4. IR spectrum of Polymer-I.

at $1000-1300 \mathrm{~cm}^{-1}$ with two bands or more. The disappearance of $\mathrm{OH}$ stretching frequency of the acid at 2500 $3000 \mathrm{~cm}^{-1}$ further confirms the formation of polyester group.

The NMR spectrum of Polymer I could not be done due to its insolubility but the IR spectrum (Figure 4) gives the confirmation about the formation of ester group.

The $400 \mathrm{MHz}$ spectrum of Polymer II is presented in Figure 6. It consists of $\delta 8.8-8.2 \mathrm{ppm}$ is due to imine 


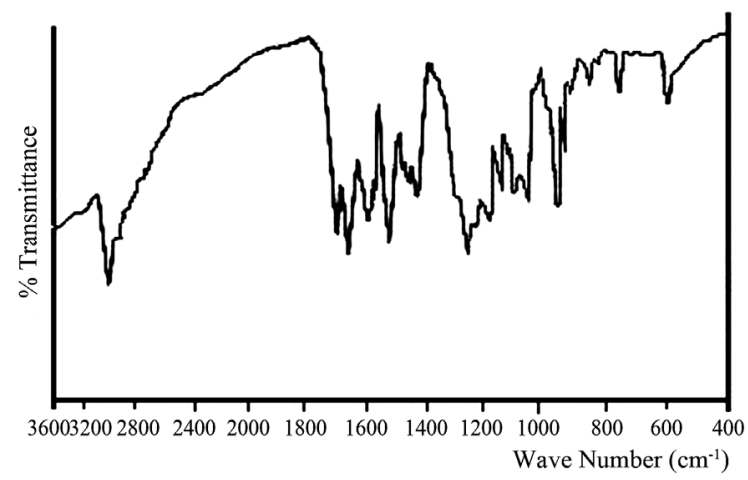

Figure 5. IR spectrum of Polymer-II.

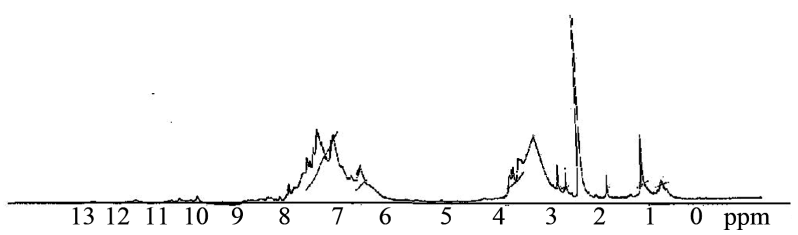

Figure 6. ${ }^{\mathrm{I}} \mathrm{H}-\mathrm{NMR}$ spectrum of Polymer-II.

protons, $\delta 7.7$ - $6.5 \mathrm{ppm}$ broad and overlapping peaks due to aromatic protons and $\delta 3.83 \mathrm{ppm}$ and $\delta 3 \mathrm{ppm}$ are due to $\mathrm{OCH}_{3}$ and $\mathrm{CH}_{2}$ protons.

The characteral evidence as supplied by the IR spectra of Polymer I \& II and the ${ }^{1} \mathrm{H}-\mathrm{NMR}$ spectrum of Polymer I confirmed the formation of the polymer and supports the synthetic route adopted.

\subsection{Solubility}

The solubility of Polymers I \& II was checked with polar and non polar solvents (Table 2). Polymer I was highly insoluble and its solubility in conc. $\mathrm{H}_{2} \mathrm{~S}_{4}$ could not be done due to the scission of azomethine linkage [39]. This was evidenced by the IR spectra of the polymers recorded by Saegu et al., before and after viscosity measurements [40]. The presence of ether group at the back bone offers highest degree of insolubility. The in- troduction of pendent group does not improve the solubility in Polymer I.

Polymer II was found to be soluble in all polar and some of the non polar solvents. It must be due to the presence of flexible methylene group in the back bone and the pendent group in the side chain. The viscosity of Polymer II with DMF is $0.25 \mathrm{~g} / \mathrm{dl}$.

It was found that polymer with the oxygen atom and higher number of aromatic rings in the backbone had high degree of crystallinity and poor solubility. Polymer with methylene spacer at the backbone showed good solubility.

\subsection{Thermal Analysis}

The thermal stability of the polymers was investigated by TGA and the weight loss curve is presented in Figure 7. The weight loss data for the polymers are given in Table 3.

It suggests that, both the polymers have good thermal stability as the starting weight loss for the polymers situated within the $257^{\circ} \mathrm{C}-262^{\circ} \mathrm{C}$. The weight loss curve gives the degradation process in nitrogen and it presents two stages, one main weight loss $257^{\circ}-262^{\circ}$ (ester linkage) and $285^{\circ} \mathrm{C}-335^{\circ} \mathrm{C}$ ranges. When compared with similar structure and high temperature it can be confirmed that $-\mathrm{N}=\mathrm{CH}$ - group is breaking at the second stage weight loss $[41,42]$.

\subsection{Liquid Crystalline Studies}

When the polymers were subjected to liquid crystalline properties, Polymer I has not shown any liquid crystalline nature which may be due to the presence of higher number of aromatic rings present at the back-bone. But Polymer II had shown Nematic Schlerien structure (Figure 8), which may be due to the incorporation of flexible methylene spacers and lesser number of aromatic groups in the back-bone.

Table 2. Solubility data of polymers.

\begin{tabular}{cccccccccc}
\hline \multirow{2}{*}{ Polymer } & \multicolumn{10}{c}{ Solvents } \\
\cline { 2 - 9 } & DMF & DMSO & DMAc & NMP & Toluene & Benzene & Acetone & Methanol & Ethanol \\
\hline Polymer-I & $\bullet \bullet$ & $\bullet \bullet$ & $\bullet \bullet$ & $\bullet$ & $\bullet$ & $\bullet$ & $\bullet \bullet$ & $\bullet \bullet$ & $\bullet$ \\
Polymer-II & $\circ \circ$ & $\circ \circ$ & $\circ \circ$ & $\circ \circ$ & $\bullet$ & $\bullet$ & $\bullet \circ$ & $\circ$ & $\circ 0$ \\
\hline
\end{tabular}

$\bullet \bullet-I n s o l u b l e ; ~ \circ ০-S o l u b l e ; \bullet \circ-P a r t i a l l y ~ s o l u b l e$.

Table 3. Thermal stability of polymers.

\begin{tabular}{cccc}
\hline \multirow{2}{*}{ Polymer } & \multicolumn{3}{c}{ Thermal stability } \\
\cline { 2 - 4 } & $10 \%$ weight loss temperature ${ }^{\circ} \mathrm{C}$ & $20 \%$ weight loss temperature ${ }^{\circ} \mathrm{C}$ & Char residue $\left(\mathrm{wt} \%\right.$ at $\left.700^{\circ} \mathrm{C}\right)$ \\
\hline Polymer-I & 262 & 335 & 44 \\
Polymer-II & 257 & 285 & 43 \\
\hline
\end{tabular}




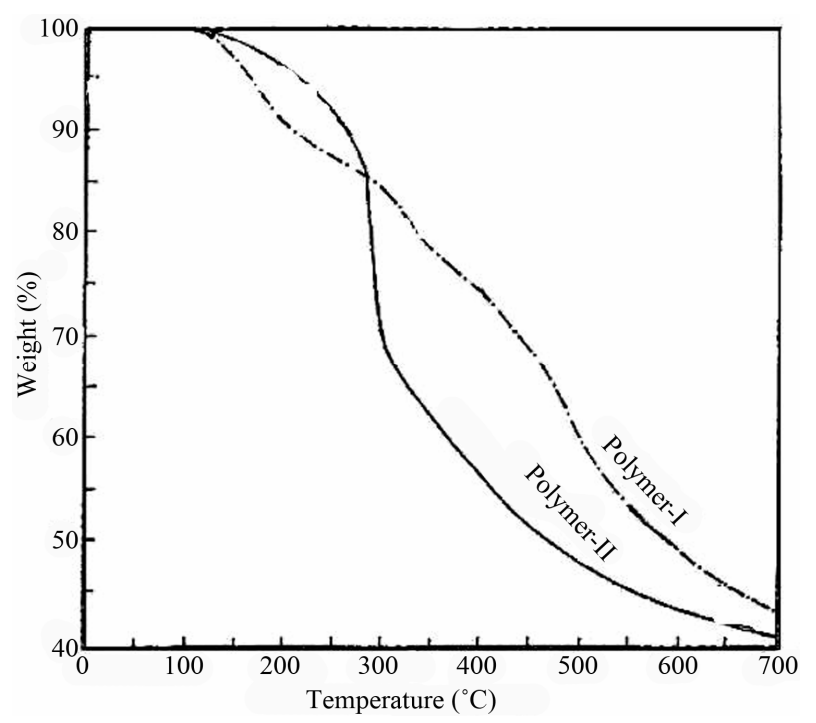

Figure 7. TGA traces of Polymer-I \& Polymer-II.

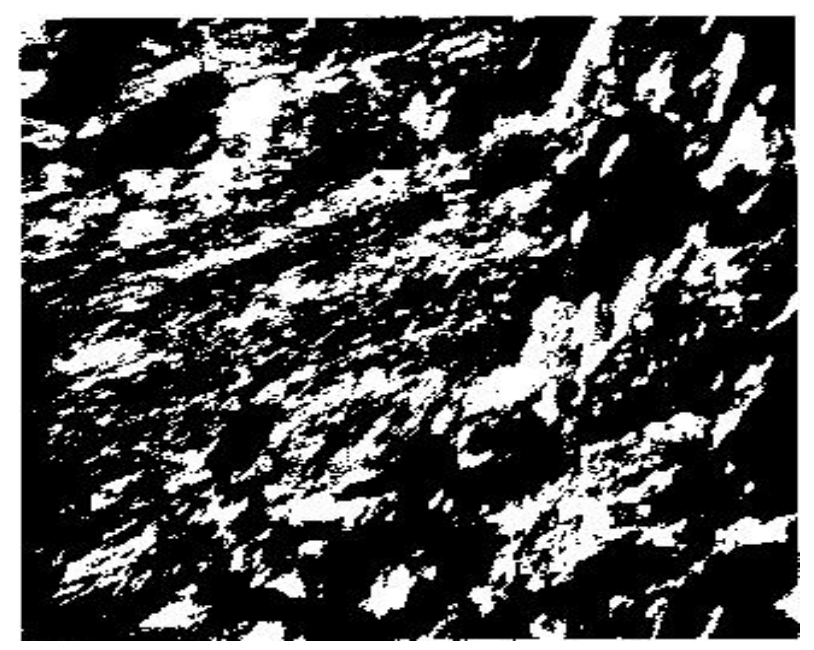

Figure 8. Nematic schlerien structure.

\section{Conclusion}

We have presented one new monomer with pendent dimethoxy benzylidene group and two new polymers.

Polymer I with oxygen atom, azomethine group at the main chain has the highest thermal stability. So far there is no report about poly(azomethine ester) with a pendent dimethoxy benzylidene group having such high thermal stability. Presence of $-\mathrm{CH}=\mathrm{N}$ - in the main chain and as pendent, offers the scope of conductivity application for this polymer.

Polymer II showed liquid crystalline nature with good thermal stability and solubility. Till date, there is no report about poly(azomethine ester) having a pendent dimethoxy bezyledene group showing liquid crystalline nature and high solubility. These improved properties of the synthesized polymer open the door for its application in opto-electronic field.

\section{REFERENCES}

[1] K. Wada, P. E. Cassidy and W. S. Hager, Poly(azomethine-ester) Having Film-Forming Ability and Heat Resistance pre and Regulated Monomer Sequence in the Polymer Backbone," US Patent, 1991.

[2] A. Iwan, M. Palewicz, A. Sikora, J. Chmielowiec, A. Hreniak, G. Pasciak and P. Bilski," Aliphatic-Aromatic Poly(azomethine)s with Ester Groups as Thermotropic Materials for Opto(Electronic) Applications," Synthetic Metals, Vol. 160, No. 17-18, 2010, pp. 1856-1867. doi:10.1016/j.synthmet.2010.06.029

[3] D. SeK, "Liqid Crystalline Properties of Poly(Azomethine Esters)," European Polymer Journal, Vol. 20, No. 9, 1984, pp. 923-926. doi:10.1016/0014-3057(84)90174-5

[4] A. Iwan and D. Sek, "Processable Polyazomethines and Polyketanils: From Aerospace to Light Emitting Diodes and Other Advanced Applications," Progress in Polymer Science, Vol. 33, No. 3, 2008, pp. 289-345. doi:10.1016/j.progpolymsci.2007.09.005

[5] U. Shukla, K. V. Rao and A. K. Rakshit, "Thermotropic Liquid-Crystalline Polymers: Synthesis, Characterization, and Properties of Poly(azomethine esters)," Journal of Applied Polymer Science, Vol. 88, No. 1, 2003, pp. 153-160. doi:10.1002/app.11618

[6] L. Ravikumar, M. Balaji Prasad, B. J. Vasanthi, K. Gopalakrishnan, J. Rajeshkumar and V. Sengodan, "Synthesis, Characterization and Electrical Conductivity of New Poly(azomethine ester)s from Hydroxy Acids," Materials Chemistry and Physics, Vol. 115, No. 2-3, 2009, pp. 632-636. doi:10.1016/j.matchemphys.2009.01.030

[7] B. J. Vasanthi and L. Ravikumar, "Synthesis and Characterization of New Poly(azomethine ester)s Having Phenylthiourea Units," European Polymer Journal, Vol. 43, No. 10, 2007, pp. 4325-4331. doi:10.1016/j.eurpolymj.2007.07.037

[8] A. F. Khattab, "Effect of Ester Groups on Electrical Conductivity of Polyazomethine," Raf. Jou. Sci., Vol. 19, No. 2, 2008, pp. 85-88.

[9] B. Hajduk, J. Weszka, V. Cozan, B. Kaczmarczyk, B. Jarzbek and M. Domañski, "Optical Properties of Polyazomethine with Oxygen Atom in the Backbone," Archives of Materials Science and Engineering, Vol. 32, No. 2, 2008, pp. 85-88.

[10] C. S. Wang, R. W. Yang and K. R. Hsu, "Synthesis and Properties of a Novel Perfluorononenyloxy Group Containing Polyarylates," Journal of Applied Polymer Science Part A: Polymer Chemistry, Vol. 36, No. 4, 1998, pp. 645-653.

doi:10.1002/(SICI)1099-0518(199803)36:4<645::AID-P OLA13>3.0.CO;2-M

[11] F. Kakali, K. G. Gravalos and J. K. Kallitsis, "Synthesis and Characterization of Soluble Aromatic Polyesters Derived from Substituted Terphenyl and Quinquephenyl Diols," Journal of Applied Polymer Science Part A: Polymer Chemistry, Vol. 34, No. 8, 1996, pp. 1581-1588. doi:10.1002/(SICI)1099-0518(199606)34:8<1581::AID-P $\underline{\mathrm{OLA} 23>3.0 . \mathrm{CO} ; 2-3}$ 
[12] J. K. Kallitais, F. Kakali and K. G. Gravalos, "Synthesis and Characterization of Soluble Aromatic Polyesters Containing Oligophenyl Moieties in the Main Chain," Macromolecules, Vol. 27, No. 16, 1994, pp. 4509-4515. doi:10.1021/ma00094a012

[13] J. A. Mikroyannidis, "Synthesis and Characterization of Soluble, Photo Luminescent Polyamides, Polyesters, Polyesters Containing 9,10-Di(4-biphenylyl)anthracene Segments in the Main Chain," Polymer, Vol. 41, No. 23, 2000, pp. 8193-8204. doi:10.1016/S0032-3861(00)00203-2

[14] Y. T. Chern and C. M. Huang, "Synthesis and Characterization of New Polyesters Derived from 1, 6- or 4, 9Diamantanedicarboxylic Acyl Chlorides with Aryl Ether Diols," Polymer, Vol. 39, No. 11, 1998, pp. 2325-2329. doi:10.1016/S0032-3861(97)00519-3

[15] P. K. Gutch, S. Banerjee, D. C. Gupta and D. K. Jaiswal, "Poly-Schiff Bases. V. Synthesis and Characterization of Novel Soluble Fluorine-Containing Polyether Azomethines," Journal of Applied Polymer Science Part A: Polymer Chemistry, Vol. 39, No. 3, 2001, pp. 383-388. doi:10.1002/1099-0518(20010201)39:3<383::aid-pola100 5>3.0.co;2-3

[16] S. Mallakpour and E. Hashemi, "Synthesis and Characterization of Novel Optically Active and Photoactive Aromatic Polyesters Containing 1,8-Naphthalimidyl Pendant Group by Step-Growth Polymerization," Polymer Bulletin, Vol. 65, No. 6, 2010, pp. 551-563. doi:10.1007/s00289-009-0226-9

[17] N. V. Sadavarte, C. V. Avadhani and P. P. Wadgaonkar, "Synthesis and Characterization of New Organosoluble Aromatic Polyamides and Polyazomethines Containing Pendent Pentadecyl Chains," High Performance Polymers, Vol. 23, No. 7, 2011, pp. 494-505. doi: $10.1177 / 0954008311417316$

[18] H. C. Kim, J. S. Kim, K. S. Kim, H. K. Park, S. Baek and M. Ree, "Synthesis and Characterization of New, Soluble Polyazomethines Bearing Fluorine and Carbazole Units in the Backbone and Solubility-Improving Moieties in the Side Group," Journal of Applied Polymer Science Part A: Polymer Chemistry, Vol. 42. No. 4, 2004, pp. 825-834. doi:10.1002/pola.11045

[19] I. K. Spiliopoulos and J. A. Mikroyannidis, "Soluble, Rigid-Rod Polyamide, Polyimides, and Polyazomethine with Phenyl Pendent Groups Derived from 4,4'-Diamino3,5,3", 5"-Tetraphenyl-p-terphenyl," Macromolecules, Vol. 29, No. 16, 1996, pp. 5313-5319. doi:10.1021/ma9602233

[20] K. S. Lee, J .C. Won and J. C. Jung, "Synthesis and Characterization of Processable Conducting Polyazomethines," Die Makromolekulare Chemie, Vol. 190, No. 7, 1989, pp. 1547-1552. doi:10.1002/macp.1989.02190070

[21] S. B. Park, H. Kim, W. C. Zin and J. C. Jung, "Synthesis and Properties of Polyazomethines Having Flexible (n-Alkyloxy) Methyl Side Chains," Macromolecules, Vol. 26, No. 7, 1993, pp. 1627-1632. doi: $10.1021 / \mathrm{ma} 00059 \mathrm{a} 021$

[22] H. Kim, S. B. Park, J. C. Jung and W. C. Zin, "Structure and Phase Behavior of Polyazomethines Having Flexible n-Alkyloxy Methyl Side Chains," Polymer, Vol. 37, No.
13, 1996, pp. $2845-2852$. doi:10.1016/0032-3861(96)87649-X

[23] C. J. Yang and S. A. Jenekhe, "Conjugated Aromatic Poly(azomethines). 1. Characterization of Structure, Electronic Spectra, and Processing of Thin Films from Soluble Complexes," Chemistry of Materials, Vol. 3, No. 5, 1991, pp. 878-887. doi:10.1021/CM00017A025

[24] C. Wang, S. Shieh, E. LeGoff and M. G. Kanatzidis, "Synthesis and Characterization of a New Conjugated a Aromatic Poly(azomethine) Derivative Based on the 3',4'-Dibutyl- $\alpha$-terthiophene Building Block," Macromolecules, Vol. 29 , No. 9, 1996, pp. 3147-3156. doi: $10.1021 / \mathrm{ma} 9514131$

[25] S. Brocchini, K. James, V. Tangpasuthadol and J. Kohn, "A Combinatorial Approach for Polymer Design," Journal of the American Chemical Society, Vol. 119, No. 19, 1997, pp. 4553-4554. doi:10.1021/ja970389z

[26] D. J. Liaw, P. N. Hsu, J. Chen, B. Y. Liaw and C. Y. Hwang, "Synthesis and Characterization of New Soluble Polyamides Containing Phthalimide Pendent Group," Journal of Applied Polymer Science Part A: Polymer Chemistry, Vol. 39, No. 10, 2001, pp. 1557-1563. doi:10.1002/pola.1131

[27] D. J. Liaw, B. Y. Liaw, J. J. Hsu, B. Y. Liaw and Y. C. Cheng, "Synthesis and Characterization of New Soluble Polyesters Derived from Various Cardo Bisphenols by Solution Polycondensation," Journal of Applied Polymer Science Part A: Polymer Chemistry, Vol. 38, No. 24, 2000, pp. 4451-4456.

doi:10.1002/1099-0518(20001215)38:24<4451::AID-PO $\mathrm{LA} 140>3.0 . \mathrm{CO} ; 2-\mathrm{Q}$

[28] T. Matsumoto, F. Yamada and T. Kurosaki, "Fully Conjugated and Soluble Polyazomethines," Macromolecules, Vol. 30, No. 12, 1997, pp. 3547-3552. doi:10.1021/ma9614104

[29] W. Zhang, M. Shiotsuki, T. Masuda, J. Kumaki and E. Yashima, "Synthesis of Polymer Brushes Composed of Poly(phenylacetylene) Main Chain and Either Polystyrene or Poly(methyl methacrylate) Side Chains," Macromolecules, Vol. 40, No. 2, 2007, pp. 178-185. doi:10.1021/ma061964z

[30] W. Zhang, M. Shiotsuki and T. Masuda, "Synthesis and Characteristics of Poly(macromonomers) and Graft Copolymers Composed of Poly(phenylacetylene) Main Chain and Poly(ethylene oxide) Side Chains," Macromolecules, Vol. 40, No. 5, 2007, pp. 1421-1428. doi: $10.1021 / \mathrm{ma} 062290 \mathrm{v}$

[31] I. Cianga, V. M. Mercore, M. Grigoras and Y. Yagci, "Synthesis and Characteristic of Poly(macromonomers) Composed of Alternating Binaphthalene-, Phenylene Main Chain and Polystyrene Side Chains," Polymer, Vol. 48, No. 22, 2007, pp. 6501-6509. doi:10.1016/j.polymer.2007.09.002

[32] J. A. Mikroyannidis, "Aromatic Polyamides and Polyimides with Benzoxazole or Benzothiazole Pendent Groups Prepared from 5-(2-Benzoxazole)- or 5-(2-Benzothiazole)-1,3-phenylenediamine," Macromolecules, Vol. 28, No. 15, 1995, pp. 5177-5183. doi:10.1021/ma00119a003

[33] C. H. Li and T. C. Chang, "Thermotropic Liquid Crystalline Polymer. III. Synthesis and Properties of Poly(am- 
ide-azomethine-ester)," Journal of Applied Polymer Science Part A: Polymer Chemistry, Vol. 29, No. 3, 1991, pp. 361-367. doi:10.1002/pola.1991.080290309

[34] W. R. Krigbaum, R. Kotek, Y. Mihara and J. Preston, "Preparation of Polyamides via the Phosphorylation Reaction. X. A Study of Higashi Reaction Conditions," Journal of Applied Polymer Science Part A: Polymer Chemistry, Vol. 23, No. 7, 1985, pp. 1907-1916. doi:10.1002/pol.1985.170230706

[35] F. Higashi, K. Kubota and M. Sekizuka, "Preparation of Aromatic Polyesters Using Poly(ethyl phosphate) and Imidazole," Die Makromolekulare Chemie Rapid Communications, Vol. 1, No. 7, 1980, pp. 457-460. doi:10.1002/marc.1980.030010709

[36] N. Yamazaki, F. Higashi and J. Kawabata, "Studies on Reactions of the N-phosphonium Salts of Pyridines. XI. Preparation of Polypeptides and Polyamides by Means of Triaryl Phosphites in Pyridine," Journal of Applied Polymer Science Part A: Polymer Chemistry, Vol. 12, No. 9, 1974, pp. 2149-2154. doi:10.1002/pol.1974.170120935

[37] C. Rangaswamy, "Synthesis and Characterization of Polymers (Synthesis and Characterization of Certain Polyesters Containing Azo/Azomethine Groups in the Polymer Backbone)," Ph.D. Dissertation, Bharathiar University, Coimbatore, 1996.

[38] F. Higashi and A. Mochizuki, "Direct Polycondensation
Reaction with Triphenyl Phosphite Initiated by Tertiary Amine Hydrochlorides," Journal of Applied Polymer Science Part A: Polymer Chemistry, Vol. 21, No. 11, 1983, pp. 3337-3340. doi:10.1002/pol.1983.170211130

[39] F. Higashi, A. Hoshio and J. Kiyoshige, "Preparation of Aromatic Polyesters by the Direct Polycondensation Reaction with Diphenyl Chlorophosphate in Pyridine," Journal of Applied Polymer Science Part A: Polymer Chemistry, Vol. 21, No. 11, 1983, pp. 3241-3247. doi:10.1002/pol.1983.170211120

[40] O. Catenescu, M. Grigoras, G.Colotin, A. Dobreanu, N. Hurduc and C. I. Simionescu, "Synthesis and Chararacterization of Some Aliphatic Aromatic Poly(Schiff base)s," European Polymer Journal, Vol. 37, No. 11, 2001, pp. 2213-2216. doi:10.1016/S0014-3057(01)00119-7

[41] Y. Saegusa, K. Sekiba and S. Nakamura, "Synthesis and Characterization of Novel 1,3,4-Oxadiazole- or 1,3,4Thiadiazole-Containing Wholly Conjugated Polyazomethines," Journal of Applied Polymer Science Part A: Polymer Chemistry, Vol. 28, No. 13, 1990, pp. 3647-3659. doi:10.1002/pola.1990.080281311

[42] M. Grigoras and N. C. Antonoaia, "Synthesis and Characterization of Some Carbazole-Based Imine Polymers," European Polymer Journal, Vol. 41, No. 5, 2005, pp. 1079-1089. doi:10.1016/j.eurpolymj.2004.11.019 